\title{
On Welfare under Cournot and Bertrand Competition in Differentiated Oligopolies
}

\author{
Judy Hsu \\ Nanhua University \\ Taiwan \\ and \\ X. Henry Wang \\ Department of Economics \\ University of Missouri-Columbia \\ Columbia, MO 65211, USA
}

June 2005 


\begin{abstract}
Häckner (2000) shows that in a differentiated oligopoly with more than two firms, prices may be higher under Bertrand competition than under Cournot competition, implying that the classical result of Singh and Vives (1984) that Bertrand prices are always lower than Cournot prices is sensitive to the duopoly assumption. Häckner (2000), however, le aves unanswered the important question of whether welfare may be lower under price competition. This note shows that in Häckner's model both consumer surplus and total surplus are higher under price competition than under quantity competition regardless of whether goods are substitutes or complements.
\end{abstract}

\title{
JEL Numbers: D43, L13
}

Keywords: Bertrand; Cournot; Differentiated oligopoly; Welfare. 


\section{Introduction}

In their classical paper, Singh and Vives (1984) show that in a differentiated duopoly with linear demands and constant marginal costs both consumer surplus and total surplus (the sum of consumer surplus and total industry profit) are higher under Bertrand price competition than under Cournot quantity competition regardless of whether goods are substitutes or complements. This result is due to their established result that quantities are lower and prices higher in Cournot than in Bertrand competition, and the facts that consumer surplus is decreasing and convex in prices and that total surplus is increasing and concave in quantities. In a recent paper, Häckner (2000) shows that in a differentiated oligopoly with more than two firms and vertical quality differentiation, prices may be higher under price competition than under quantity competition, implying that Singh and Vives' results on prices and quantities are sensitive to the duopoly assumption. However, Häckner (2000) leaves unanswered the important question of whether welfare may be lower under price competition than under quantity competition. ${ }^{1}$

This note shows that in Häckner's model both consumer surplus and total surplus are higher under price competition than under quantity competition regardless of whether goods are substitutes or complements. Thus Singh and Vives' conclusion on welfare continues to hold in Häckner's oligopolistic model While uniform ranking of prices between Bertrand and Cournot competition guarantees a definitive ranking on welfare, it is not necessary. In Häckner's model, Bertrand prices can be higher than Cournot prices but this happens only for low-quality firms and when quality differences across firms are large. Both conditions imply that the low-quality firms have less significant effects on the overall welfare. Indeed, it is shown in the following that price reversal for low-quality firms is never significant enough to make welfare smaller under Bertrand than under Cournot competition.

\footnotetext{
1 Indeed, Häckner (2000) states that "The welfare issue becomes too complex in a general setting” (p. 233).
} 


\section{The Häckner Model}

Häckner (2000) considers an n-firm (n $\geq 3$ ) differentiated goods oligopoly model with quality differentiation that is a direct generalization of the duopoly model developed by Dixit (1979). For convenience, the same notation as in Häckner (2000) is adopted here. There is a representative consumer with the following quasilinear utility function:

$$
\mathrm{U}(\mathbf{q}, \mathrm{I})=\sum_{\mathrm{i}=1}^{\mathrm{n}} \mathrm{q}_{\mathrm{i}} \alpha_{\mathrm{i}}-\frac{1}{2}\left(\sum_{\mathrm{i}=1}^{\mathrm{n}} \mathrm{q}_{\mathrm{i}}^{2}+2 \gamma \sum_{\mathrm{i} \neq \mathrm{j}} \mathrm{q}_{\mathrm{i}} \mathrm{q}_{\mathrm{j}}\right)+\mathrm{I}
$$

In (1), $\mathbf{q}=\left(\mathrm{q}_{1}, \cdots, \mathrm{q}_{\mathrm{n}}\right)$ is the quantity vector with each $\mathrm{q}_{\mathrm{i}}$ denoting the consumer's consumption of good $i ; \alpha_{i}>0$ denotes the quality of good $i ; \gamma \in[-1,1]$ is the substitution parameter; $\mathrm{I}$ is a composite measure of the consumer's consumption of all other goods. The $\mathrm{n}$ goods are substitutes, independent or complements according as $\gamma>0,=0$, or $<0$.

Let $\mathrm{p}_{\mathrm{i}}$ denote the price of good $\mathrm{i}, \mathrm{m}$ the consumer's income, and the composite good's price be normalized to 1 . Maximizing $U(\mathbf{q}, \mathrm{I})$ subject to the budget constraint that $\sum_{\mathrm{i}=1}^{\mathrm{n}} \mathrm{p}_{\mathrm{i}} \mathrm{q}_{\mathrm{i}}+\mathrm{I} \leq \mathrm{m}$ gives the inverse demand equations:

$$
\mathrm{p}_{\mathrm{k}}=\alpha_{\mathrm{k}}-\mathrm{q}_{\mathrm{k}}-\gamma \sum_{\mathrm{j} \neq \mathrm{k}} \mathrm{q}_{\mathrm{j}}, \quad \mathrm{k}=1, \ldots, \mathrm{n}
$$

Let $\bar{\alpha}=\left(\sum_{\mathrm{i}=1}^{\mathrm{n}} \alpha_{\mathrm{i}}\right) / \mathrm{n}$ denote the average product quality. Using the inverse demand system (2) and assuming all firms produce at zero costs, Häckner (2000) derived the Cournot equilibrium prices and quantities for firm k, given by

$$
\mathrm{p}_{\mathrm{k}}^{\mathrm{C}}=\mathrm{q}_{\mathrm{k}}^{\mathrm{C}}=\frac{\bar{\alpha}}{\gamma(\mathrm{n}-1)+2}+\frac{\alpha_{\mathrm{k}}-\bar{\alpha}}{2-\gamma},
$$

and the Bertrand equilibrium prices and quantities for firm $\mathrm{k}$, given by

$$
\mathrm{p}_{\mathrm{k}}^{\mathrm{B}}=\frac{1-\gamma}{\gamma(\mathrm{n}-3)+2} \bar{\alpha}+\frac{\gamma(\mathrm{n}-1)+1}{\gamma(2 \mathrm{n}-3)+2}\left(\alpha_{\mathrm{k}}-\bar{\alpha}\right),
$$




$$
\mathrm{q}_{\mathrm{k}}^{\mathrm{B}}=\frac{\gamma(\mathrm{n}-2)+1}{[\gamma(\mathrm{n}-3)+2][\gamma(\mathrm{n}-1)+1]} \bar{\alpha}+\frac{\gamma(\mathrm{n}-2)+1}{(1-\gamma)[\gamma(2 \mathrm{n}-3)+2]}\left(\alpha_{\mathrm{k}}-\bar{\alpha}\right) .
$$

Here, (3)-(5) are expressed in a form that will facilitate later calculations. As can be seen from (3)-(5), equilibrium prices and quantities for each good $\mathrm{k}$ are linear combinations of the average quality and the difference between good k's quality and the average quality. These relationships will help us to express both consumer surplus and total surplus as linear combinations of the average quality squared and the variance of product quality.

\section{Bertrand vs. Cournot: Welfare Comparison}

Let $\alpha=\left(\alpha_{1}, \cdots, \alpha_{\mathrm{n}}\right)$ denote the quality vector and $\mathbf{A}$ the following $\mathrm{n} \times \mathrm{n}$ matrix:

$$
\mathbf{A}=\left[\begin{array}{lccc}
1 & \gamma & \cdots & \gamma \\
\gamma & 1 & \cdots & \gamma \\
\vdots & \vdots & \ddots & \vdots \\
\gamma & \gamma & \cdots & 1
\end{array}\right]
$$

Then the representative consumer's utility function (1) can be rewritten as $\mathrm{U}(\mathbf{q}, \mathrm{I})=\alpha \mathbf{q}^{\prime}-\mathbf{q} \mathbf{A} \mathbf{q} \mathbf{q}^{\prime} / 2+\mathrm{I}$ and the maximizing conditions (2) can be rewritten as $\mathbf{p}=\alpha-\mathbf{q A}$, where $\mathbf{p}=\left(\mathrm{p}_{1}, \cdots, \mathrm{p}_{\mathrm{n}}\right)$ is the price vector. Hence consumer surplus (CS) is given by

$$
\mathrm{CS}=\mathrm{U}(\mathbf{q}, \mathrm{I})-\left(\mathbf{p q}^{\prime}+\mathrm{I}\right)=\mathbf{q} \mathbf{A q}^{\prime} / 2
$$

Applying to this expression the matrix identity that $\mathbf{A}=(1-\gamma) \mathbf{I}_{\mathbf{n}}+\gamma \mathbf{1}_{\mathbf{n}}$ where $\mathbf{I}_{\mathbf{n}}$ is the $\mathrm{n} \times \mathrm{n}$ identity matrix and $\mathbf{1}_{\mathbf{n}}$ is the $\mathrm{n} \times \mathrm{n}$ matrix of all 1 's, one obtains

$$
\mathrm{CS}=\frac{1-\gamma}{2} \sum_{\mathrm{i}=1}^{\mathrm{n}} \mathrm{q}_{\mathrm{i}}^{2}+\frac{\gamma}{2}\left(\sum_{\mathrm{i}=1}^{\mathrm{n}} \mathrm{q}_{\mathrm{i}}\right)^{2}=\frac{1-\gamma}{2} \sum_{\mathrm{i}=1}^{\mathrm{n}}\left(\mathrm{q}_{\mathrm{i}}-\overline{\mathrm{q}}\right)^{2}+\frac{\mathrm{n}[\gamma(\mathrm{n}-1)+1]}{2}(\overline{\mathrm{q}})^{2}
$$

where $\overline{\mathrm{q}}=\left(\sum_{\mathrm{i}=1}^{\mathrm{n}} \mathrm{q}_{\mathrm{i}}\right) / \mathrm{n}$ is the average quantity.

Under Cournot competition, average quantity is $\overline{\mathrm{q}}^{\mathrm{C}}=\frac{\bar{\alpha}}{\gamma(\mathrm{n}-1)+2}$ and $\mathrm{q}_{\mathrm{k}}^{\mathrm{C}}-\overline{\mathrm{q}}^{\mathrm{C}}=\frac{\alpha_{\mathrm{k}}-\bar{\alpha}}{2-\gamma}$.

Substituting these into (6) gives the consumer surplus under Cournot competition: 


$$
\mathrm{CS}^{\mathrm{C}}=\frac{\mathrm{n}(1-\gamma)}{2(2-\gamma)^{2}} \sigma_{\alpha}^{2}+\frac{\mathrm{n}[\gamma(\mathrm{n}-1)+1]}{2[\gamma(\mathrm{n}-1)+2]^{2}}(\bar{\alpha})^{2}
$$

where $\sigma_{\alpha}^{2}=\left(\sum_{\mathrm{i}=1}^{\mathrm{n}}\left(\alpha_{\mathrm{i}}-\bar{\alpha}\right)^{2}\right) / \mathrm{n}$ is the variance of product quality. Similarly, by use of (5) and (6), the consumer surplus under Bertrand competition is

$$
\mathrm{CS}^{\mathrm{B}}=\frac{\mathrm{n}[\gamma(\mathrm{n}-2)+1]^{2}}{2(1-\gamma)[\gamma(2 \mathrm{n}-3)+2]^{2}} \sigma_{\alpha}^{2}+\frac{\mathrm{n}[\gamma(\mathrm{n}-2)+1]^{2}}{2[\gamma(\mathrm{n}-3)+2]^{2}[\gamma(\mathrm{n}-1)+1]}(\bar{\alpha})^{2} .
$$

Total surplus (TS) is the sum of consumer surplus and total industry profit $\left(\Pi=\sum_{\mathrm{i}=1}^{\mathrm{n}} \mathrm{p}_{\mathrm{i}} \mathrm{q}_{\mathrm{i}}\right)$.

By utilizing (3), the total profit under Cournot competition is

$$
\Pi^{\mathrm{C}}=\sum_{\mathrm{i}=1}^{\mathrm{n}}\left(\mathrm{q}_{\mathrm{i}}^{\mathrm{C}}\right)^{2}=\sum_{\mathrm{i}=1}^{\mathrm{n}}\left(\mathrm{q}_{\mathrm{i}}^{\mathrm{C}}-\overline{\mathrm{q}}^{\mathrm{C}}\right)^{2}+\mathrm{n}\left(\overline{\mathrm{q}}^{\mathrm{C}}\right)^{2}=\frac{\mathrm{n}}{(2-\gamma)^{2}} \sigma_{\alpha}^{2}+\frac{\mathrm{n}}{[\gamma(\mathrm{n}-1)+2]^{2}}(\bar{\alpha})^{2} .
$$

By use of (4) and (5), the total profit under Bertrand competition is

$$
\begin{aligned}
\Pi^{B} & =\frac{(1-\gamma)[\gamma(n-1)+1]}{\gamma(n-2)+1} \sum_{i=1}^{n}\left(q_{i}^{B}\right)^{2}=\frac{(1-\gamma)[\gamma(n-1)+1]}{\gamma(n-2)+1}\left[\sum_{i=1}^{n}\left(q_{i}^{B}-\bar{q}^{B}\right)^{2}+n\left(\bar{q}^{B}\right)^{2}\right] \\
& =\frac{n[\gamma(n-1)+1][\gamma(n-2)+1]}{(1-\gamma)[\gamma(2 n-3)+2]^{2}} \sigma_{\alpha}^{2}+\frac{n(1-\gamma)[\gamma(n-2)+1]}{[\gamma(n-3)+2]^{2}[\gamma(n-1)+1]}(\bar{\alpha})^{2} .
\end{aligned}
$$

Summing (7) and (9) gives the total surplus under Cournot competition

$$
\mathrm{TS}^{\mathrm{C}}=\frac{\mathrm{n}(3-\gamma)}{2(2-\gamma)^{2}} \sigma_{\alpha}^{2}+\frac{\mathrm{n}[\gamma(\mathrm{n}-1)+3]}{2[\gamma(\mathrm{n}-1)+2]^{2}}(\bar{\alpha})^{2} .
$$

Summing (8) and (10) gives the total surplus under Bertrand competition

$$
\mathrm{TS}^{\mathrm{B}}=\frac{\mathrm{n}[\gamma(\mathrm{n}-2)+1][\gamma(3 \mathrm{n}-4)+3]}{2(1-\gamma)[\gamma(2 \mathrm{n}-3)+2]^{2}} \sigma_{\alpha}^{2}+\frac{\mathrm{n}[\gamma(\mathrm{n}-2)+1][\gamma(\mathrm{n}-4)+3]}{2[\gamma(\mathrm{n}-3)+2]^{2}[\gamma(\mathrm{n}-1)+1]}(\bar{\alpha})^{2} .
$$

The preceding expressions indicate that both consumer surplus and total surplus are expressible as linear combinations of the variance of product quality and the average quality squared. The following proposition shows that both coefficients in these linear combinations are greater under Bertrand than under Cournot competition, resulting in larger consumer surplus and total surplus under Bertrand than under Cournot competition. 
Proposition 1. Consumer surplus and total surplus are higher under Bertrand than under Cournot competition regardless of whether goods are substitutes or complements; they are equal in Bertrand and Cournot competition when goods are independent.

Proof. As in Häckner (2000), we assume that $\gamma>-1 /(n-1)$, i.e., the second-order condition for an interior solution under Bertrand competition holds. ${ }^{2}$ Consider first consumer surplus. Taking the difference between (7) and (8) gives

$$
\begin{aligned}
& C S^{C}-C S^{B} \\
& =\frac{n(n-1) \gamma^{2}}{2}\left\{\frac{\gamma^{2}(3 n-5)-2 \gamma(2 n-5)-4}{(2-\gamma)^{2}[\gamma(2 n-3)+2]^{2}} \sigma_{\alpha}^{2}-\frac{\gamma^{2}\left(2 n^{2}-7 n+5\right)+2 \gamma(3 n-5)+4}{[\gamma(n-1)+2]^{2}[\gamma(n-3)+2]^{2}[\gamma(n-1)+1]}\left(\bar{\alpha}^{2}\right\} .\right.
\end{aligned}
$$

Obviously, $C S^{C}-C S^{B}$ is equal to zero when $\gamma=0$. For $\gamma \neq 0$, the sign of $C S^{C}-C^{B}$ depends on the signs of the two numerators inside the above braces; it is negative if the first numerator is negative and the second numerator is positive. The first numerator (i.e., $\left.\gamma^{2}(3 n-5)-2 \gamma(2 n-5)-4\right)$ is a U-shaped function of $\gamma$; it is negative for all $\gamma$ in the interval $\left(\left(2 n-5-\sqrt{4 n^{2}-8 n+5}\right) /(3 n-5)\right.$, $\left.\left(2 n-5+\sqrt{4 n^{2}-8 n+5}\right) /(3 n-5)\right)$. It is easy to verify that this interval includes $(-1 /(n-1), 1]$ as a subinterval for all $n \geq 3$. Hence, the first numerator in the above braces is negative provided $\gamma>-1 /(n-1)$ and $n \geq 3$. The second numerator (1.e., $\gamma^{2}\left(2 n^{2}-7 n+5\right)+2 \gamma(3 n-5)+4$ ) is also Ushaped in $\gamma$; it is positive for all $\gamma>\left[-(3 n-5)+\sqrt{n^{2}-2 n+5}\right] /\left(2 n^{2}-7 n+5\right)$, which is less than $-1 /(n-1)$ for all $n \geq 3$. Hence, the second numerator in the above braces is positive provided $\gamma>-1 /(n-1)$ and $n \geq 3$. We have thus shown that $\mathrm{CS}^{\mathrm{C}}-\mathrm{CS}^{\mathrm{B}}<0$ except when $\gamma=0$, in which case the difference is equal to zero.

Consider next total surplus. Taking the difference between (11) and (12) yields

\footnotetext{
${ }^{2}$ Also as in Häckner (2000), we assume here that all firms produce a positive level of output under both Cournot and Bertrand competition.
} 


$$
\begin{aligned}
& \mathrm{TS}^{\mathrm{C}}-\mathrm{TS}^{\mathrm{B}} \\
& =\frac{\mathrm{n}(\mathrm{n}-1) \gamma^{2}}{2}\left\{\frac{\gamma^{2}(\mathrm{n}-1)-2 \gamma(2 \mathrm{n}-3)-4}{(1-\gamma)(2-\gamma)^{2}[\gamma(2 \mathrm{n}-3)+2]^{2}} \sigma_{\alpha}^{2}+\frac{\gamma^{2}(\mathrm{n}-1)-2 \gamma(\mathrm{n}-3)-4}{[\gamma(\mathrm{n}-1)+2]^{2}[\gamma(\mathrm{n}-3)+2]^{2}[\gamma(\mathrm{n}-1)+1]}(\bar{\alpha})^{2}\right\}
\end{aligned}
$$

Obviously, $\mathrm{TS}^{\mathrm{C}}-\mathrm{TS}^{\mathrm{B}}$ is equal to zero when $\gamma=0$. For $\gamma \neq 0$, the sign of $\mathrm{TS}^{\mathrm{C}}-\mathrm{TS}^{\mathrm{B}}$ is determined by the signs of the two numerators inside the above braces. The first numerator (i.e., the expression: $\left.\gamma^{2}(n-1)-2 \gamma(2 n-3)-4\right)$ is a U-shaped function of $\gamma$; it is negative for all $\gamma$ in the interval $\left(\left(2 n-3-\sqrt{4 n^{2}-8 n+5}\right) /(n-1),\left(2 n-3+\sqrt{4 n^{2}-8 n+5}\right) /(n-1)\right)$. It is easy to verify that this interval includes $(-1 /(n-1), 1]$ as a subinterval for all $n \geq 3$. Hence, the first numerator in the above braces is negative provided that $\gamma>-1 /(n-1)$ and $n \geq 3$. The second numerator $\left(\gamma^{2}(n-1)-2 \gamma(n-3)-4\right)$ is also a U-shaped function of $\gamma$; it is negative for all $\gamma$ in the interval $\left(\left(n-3-\sqrt{n^{2}-2 n+5}\right) /(n-1)\right.$, $\left.\left(n-3+\sqrt{n^{2}-2 n+5}\right) /(n-1)\right)$. It is easy to verify that this interval includes $(-1 /(n-1), 1]$ as a subinterval for all $\mathrm{n} \geq 3$. Hence, the second numerator in the above braces is negative provided that $\gamma>-1 /(n-1)$ and $n \geq 3$. We have thus shown that $\mathrm{TS}^{\mathrm{C}}-\mathrm{TS}^{\mathrm{B}}<0$ except when $\gamma=0$, in which case the difference is equal to zero.

\section{Discussion}

Häckner (2000) shows that, in a differentiated goods oligopoly with three or more firms, if quality differences are large and goods are complementary low-quality firms may charge higher prices under Bertrand than under Cournot competition. The reason for this result is the asymmetric effects that switching from quantity to price competition has on firms of different qualities. Compared to quantity competition, prices are lower and demands higher for high-quality producers (i.e., the large firms) under price competition. With complementary goods and a substitution rate that is uniform across all goods, the demand for low-quality goods may become so high under price competition that it enables low-quality producers to charge prices that are higher than those under quantity competition. 
While Häckner is silent on welfare comparisons, this note has shown that in Häckner's model Bertrand competition leads to higher consumer surplus and total surplus than Cournot competition regardless of whether goods are substitutes or complements. The reason behind our result is the following. Firm k's output share is $s_{k}^{B}=\frac{q_{k}^{B}}{Q^{B}}=\frac{1}{n}+\frac{[\gamma(n-3)+2][\gamma(n-1)+1]}{n(1-\gamma)[\gamma(2 n-3)+2]} \cdot \frac{\alpha_{k}-\bar{\alpha}}{\bar{\alpha}}$ in the Bertrand equilibrium and is $\mathrm{s}_{\mathrm{k}}^{\mathrm{C}}=\frac{\mathrm{q}_{\mathrm{k}}^{\mathrm{C}}}{\mathrm{Q}^{\mathrm{C}}}=\frac{1}{\mathrm{n}}+\frac{\gamma(\mathrm{n}-1)+2}{\mathrm{n}(2-\gamma)} \cdot \frac{\alpha_{\mathrm{k}}-\bar{\alpha}}{\bar{\alpha}}$ in the Cournot equilibrium. ${ }^{3}$ In either equilibrium output levels are ranked completely by quality with the highest quality firm selling the most and the lowest quality firm selling the least. The difference between the output shares above is $s_{k}^{B}-s_{k}^{C}=\frac{(n-1) \gamma^{3}}{(1-\gamma)(2-\gamma)[\gamma(2 n-3)+2]} \cdot \frac{\alpha_{k}-\bar{\alpha}}{\bar{\alpha}}$, which increases in quality $\alpha_{k}$ and is positive (i.e., $s_{k}^{B}>s_{k}^{C}$ ) for all firms with above average quality and negative (i.e., $s_{k}^{B}<s_{k}^{C}$ ) for all firms with below average quality. Hence, switching from Cournot to Bertrand competition, all firms with above average quality obtain larger output shares with the highest quality firm gaining the most in output share and all firms with below average quality levels receive smaller output shares with the lowest quality firm losing the most in output share. It follows that low-quality firms have insignificant effects on the overall welfare. Indeed, Proposition 1 has shown that price increases for low-quality firms are never significant enough to make welfare smaller under Bertrand than under Cournot competition.

\footnotetext{
${ }^{3}$ It is worth noting that total industry output is $Q^{B}=n \bar{\alpha}(\gamma(n-2)+1) /[(\gamma(n-3)+2)(\gamma(n-1)+1)]$ under Bertrand competition and is $\mathrm{Q}^{\mathrm{C}}=\mathrm{n} \bar{\alpha} /[\gamma(\mathrm{n}-1)+2]$ under Cournot competition. It follows that total (and also average) output is higher and average price lower under Bertrand than under Cournot competition.
} 


\section{Acknowledgements}

We wish to thank Professor Lawrence White for valuable suggestions.

\section{References}

Dixit, Avinash (1979) A Model of Duopoly Suggesting a Theory of Entry Barriers, Bell Journal of Economics, 10, 20-32.

Häckner, Jonas (2000) A Note on Price and Quantity Competition in Differentiated Oligopolies, Journal of Economic Theory, 93, 233-239.

Singh, Nirvikar and Xavier Vives (1984) Price and Quantity Competition in a Differentiated Duopoly, Rand Journal of Economics, 15, 546-554. 